\title{
Cervical Spinal Cord Compression and Sleep-Disordered Breathing in Syndromic Craniosynostosis
}

\author{
(D)B.K. den Ottelander, (D) R. de Goederen, (D).A. de Planque, (D).J. Baart, (D) M.L.C. van Veelen, (D) L.J.A. Corel, (D).F.M. Joosten,
} (DI.M.J. Mathijssen, and (D)M.H.G. Dremmen

\begin{abstract}
BACKGROUND AND PURPOSE: Cerebellar tonsillar herniation arises frequently in syndromic craniosynostosis and causes central and obstructive apneas in other diseases through spinal cord compression. The purposes of this study were the following: 1) to determine the prevalence of cervical spinal cord compression in syndromic craniosynostosis, and 2) to evaluate its connection with sleep-disordered breathing.
\end{abstract}

MATERIALS AND METHODS: This was a cross-sectional study including patients with syndromic craniosynostosis who underwent MR imaging and polysomnography. Measures encompassed the compression ratio at the level of the odontoid process and foramen magnum and the cervicomedullary angle. MR imaging studies of controls were included. Linear mixed models were developed to compare patients with syndromic craniosynostosis with controls and to evaluate the association between obstructive and central sleep apneas and MR imaging parameters.

RESULTS: One hundred twenty-two MR imaging scans and polysomnographies in 89 patients were paired; 131 MR imaging scans in controls were included. The mean age at polysomnography was 5.7 years (range, 0.02-18.9 years). The compression ratio at the level of the odontoid process was comparable with that in controls; the compression ratio at the level of the foramen magnum was significantly higher in patients with Crouzon syndrome $(+27.1, P<.001)$. The cervicomedullary angle was significantly smaller in Apert, Crouzon, and Saethre-Chotzen syndromes $\left(-4.4^{\circ}, P=.01 ;-10.2^{\circ}, P<.001 ;-5.2^{\circ}, P=.049\right)$. The compression ratios at the level of the odontoid process and the foramen magnum, the cervicomedullary angle, and age were not associated with obstructive apneas $(P>.05)$. Only age was associated with central apneas $(P=.02)$.

CONCLUSIONS: The prevalence of cervical spinal cord compression in syndromic craniosynostosis is low and is not correlated to sleep disturbances. However, considering the high prevalence of obstructive sleep apnea in syndromic craniosynostosis and the low prevalence of compression and central sleep apnea in our study, we would, nevertheless, recommend a polysomnography in case of compression on MR imaging studies.

ABBREVIATIONS: $\mathrm{CAHI}=$ central apnea-hypopnea index; $\mathrm{CMA}=$ cervicomedullary angle; $\mathrm{CR}-1=$ compression ratio at the level of the odontoid process; $\mathrm{CR}-2$ = compression ratio at the level of the foramen magnum; OAHI = obstructive apnea-hypopnea index; OSA = obstructive sleep apnea; PSG = polysomnography

S yndromic craniosynostosis, such as Apert, Crouzon, Muenke, and Saethre-Chotzen syndromes, includes premature fusion of calvarial sutures in the presence of a genetic mutation and other anomalies. ${ }^{1}$ Additional anomalies differ per syndrome and include but are not limited to midface hypoplasia, exorbitism, hearing loss, visual disturbances such as strabismus and amblyopia, and

Received May 29, 2020; accepted after revision August 19.

From the Dutch Craniofacial Center (B.K.d.O., R.D.G., C.A.d.P., I.M.J.M.), Department of Plastic and Reconstructive Surgery and Hand Surgery; Department of Neurosurgery (M.L.C.v.V.); Pediatric Intensive Care Unit (L.J.A.C., K.F.M.J.); and Department of Radiology (M.H.G.D.), Erasmus MC Sophia Children's Hospital, University Medical Center Rotterdam, Rotterdam, the Netherlands; and Department of Biostatistics (S.J.B.), Erasmus MC, University Medical Center Rotterdam, Rotterdam, the Netherlands. behavioral problems. ${ }^{2-5}$ Patients with syndromic craniosynostosis are at risk of developing intracranial hypertension, which is associated with the presence of craniocerebral disproportion, venous hypertension, obstructive sleep apnea (OSA), and CSF outflow obstruction leading to hydrocephalus. ${ }^{6-9}$

Sleep disturbances are a well-known issue in patients with syndromic craniosynostosis. OSA is the most common sleep disorder

Please address correspondence to Bianca K. den Ottelander, MD, Dutch Craniofacial Center, Sophia Children's Hospital, Erasmus University Medical Center Wytemaweg 80, 2015 CN, Rotterdam, the Netherlands; e-mail: b.denottelander@erasmusmc.nl

Indicates article with supplemental on-line photo.

http://dx.doi.org/10.3174/ajnr.A6881 
and arises mainly in Apert and Crouzon syndromes because of severe distortion of the midface anatomy. As a consequence, the prevalence of OSA varies among the syndromes and ranges between $10 \%$ and $70 \%{ }^{8,10}$ Central sleep apnea is less common, arises in approximately $4 \%$ of the patients, and seems to improve with age. ${ }^{11}$ OSA is an important risk factor for the development of intracranial hemorrhage in syndromic craniosynostosis and potentially leads to developmental issues and cardiovascular and metabolic morbidity in children in general. ${ }^{12-16}$ Likewise, sleepdisordered breathing is associated with a lower quality of life. ${ }^{15}$

Cerebellar tonsillar herniation is frequently diagnosed in syndromic craniosynostosis and is known to cause central and obstructive apneas in other diseases through spinal cord compression. ${ }^{17-22}$ Previous research showed that Chiari I malformations are not associated with central sleep apneas in syndromic craniosynostosis. ${ }^{23}$ However, compression of the cervical spinal cord itself was not evaluated. Patients with syndromic craniosynostosis might be at risk for compression of the spinal cord itself at several levels. First, compression at the level of the foramen magnum may exist before patients develop a Chiari I malformation, because the cerebellar tonsils are present in the foramen magnum even when patients have a tonsillar descent of $<5 \mathrm{~mm} .{ }^{24}$ Second, the configuration of the craniocervical junction is altered in syndromic craniosynostosis, and an altered position of the dens with respect to the foramen magnum may cause ventral brain stem compression. $^{25}$

The purposes of this study were the following: 1) to determine the prevalence of cervical spinal cord compression in syndromic craniosynostosis, and 2) to evaluate its connection with sleepdisordered breathing. On the basis of previous research, we hypothesized that there is no association between cervical spinal cord compression and sleep-disordered breathing in syndromic craniosynostosis.

\section{MATERIALS AND METHODS}

We included all patients who were born between 1990 and 2017 with syndromic craniosynostosis (Apert, Crouzon, Muenke, and Saethre-Chotzen syndromes) and treated at the Dutch Craniofacial Center, Rotterdam, the Netherlands. Children born after 2005 were prospectively included. Patients who did not undergo polysomnography (PSG) and MR imaging examinations were excluded. Institutional review board approval was obtained (MEC-2005-273, 2016-312); informed consent was waived by the institutional review board because these examinations are a part of standard care. MR imaging examinations and sleep studies were paired on the basis of the time interval between the MR imaging scan and the sleep study: Within the first year of life, the maximum time interval was 3 months, whereas a 1-year time interval was the maximum in children 1 year of age or older. MR imaging examinations of healthy controls were included to compare spinal cord parameters in craniosynostosis and controls.

\section{Neuroimaging}

All MR imaging studies were acquired with a $1.5 \mathrm{~T}$ scanner (Signa Excite HD; GE Healthcare) and were a part of standard care. The imaging protocol included a 3D T2-weighted MR image with isometric voxels (imaging parameters: section thickness, $1.6 \mathrm{~mm}$; no section gap; FOV, $20 \mathrm{~cm}$; matrix size, $224 \times 224$; TE, $90 \mathrm{~ms}$; and TR, $2500 \mathrm{~ms}$ ); and a 3D echo-spoiled gradient-echo T1-weighted MR image (imaging parameters: section thickness, $2 \mathrm{~mm}$; no section gap; FOV, $22.4 \mathrm{~cm}$; matrix size, $224 \times 224$; TE, $3.1 \mathrm{~ms}$; and TR, $9.9 \mathrm{~ms}$ ). A 3D reformatting platform (AquariusNET; TeraRecon) was used to align scans in all planes and to perform the measurements. Three measurements were performed to evaluate the presence and extent of spinal cord compression:

1. The compression ratio at the level of the odontoid process (CR-1) was measured on the axial planes on the 3D T2weighted sequence (Figure). CR-1 is associated with symptomatic myelopathy in conditions other than syndromic craniosynostosis when it is $<0.40 .^{26}$ The formula used was the following:

$\frac{\text { Anterior- Posterior Diameter of the Spinal Cord }(\mathrm{mm})}{\text { Latero- Lateral Diameter of the Spinal Cord }(\mathrm{mm})}$.

To establish consistency in all measurements, we aligned the axial plane perpendicular to the spinal cord in the sagittal plane.

2. The compression ratio at the level of the foramen magnum (CR-2) was calculated as follows:

$\frac{\text { Area Spinal Cord }(\mathrm{mm})}{\text { Foramen Magnum Area }\left(\mathrm{mm}^{2}\right)-\text { Area Cerebellar Tonsils }} \times 100$. (if present in $\mathrm{mm}^{2}$ )

See the Figure for an example. The CR-2 was measured on the 3D T1-weighted sequences. CR-2 was used as a derivative of the "crowdedness" at the level of the foramen magnum.

3. The cervicomedullary angle (CMA, in degrees) was measured at the midsagittal planes on the $3 \mathrm{D} \mathrm{T} 2$-weighted sequence and was defined as the angle between the line parallel to the ventral surface of the medulla and the line parallel to the ventral surface of the upper cervical cord (Figure). The CMA can be used to quantify the amount of basilar invagination and has been correlated to clinical evidence of brain stem compression/myelopathy when the angle is $<135^{\circ} .{ }^{27,28}$

\section{Controls}

To compare CR-1, CR-2, and the CMA in syndromic craniosynostosis versus the healthy population, we included controls in the study. The control group consisted of subjects who were scanned for clinical reasons (eg, cholesteatoma, Epileptic insult, trauma, headaches) but had no intracranial pathology on the MR image or during follow-up.

\section{Interrater Reliability}

All measurements were performed by the first author (B.K.d.O.); additional measurements by the third author (C.A.d.P.) were used to calculate the interrater reliability. Both observers had $>1$ year of experience in measuring skull base parameters in children with syndromic craniosynostosis and were supervised by M.H.G.D., who is an experienced pediatric neuroradiologist. To assess the interrater reliability, the intraclass correlation coefficient was calculated for the above-stated measurements. 


\section{Sleep Studies}

All patients underwent routine clinical or ambulant sleep studies. Scoring of the PSGs was performed according to the 2012 update of the American Association of Sleep Medicine manual for the scoring of sleep and associated events. ${ }^{29}$ For the evaluation of obstructive events, we calculated the obstructive apnea-hypopnea index (oAHI): the number of obstructive and mixed apneas and obstructive hypopneas with desaturation/arousal, divided by the total sleep time. The oAHI includes a measure to quantify OSA and is usually classified as mild (oAHI, $\geq 1-5$ ), moderate (oAHI, $\geq 5-10$ ) or severe (oAHI, $\geq 10$ ). Central breathing difficulties were evaluated by calculation of the central apnea-hypopnea index (cAHI): the number of central and mixed apneas and hypopneas with desaturation, divided by the total sleep time. Findings of the cAHI are abnormal if they are $>5 .{ }^{29}$

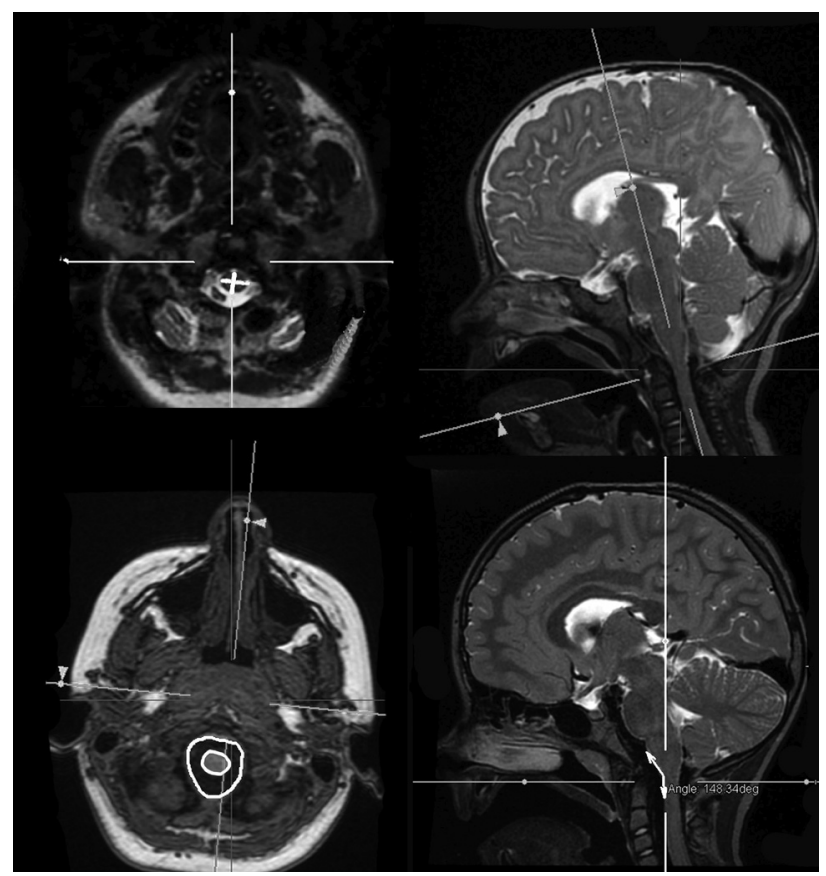

FIGURE. Axial and sagittal T2-weigthed MR imageing at the level of the odontoid process (above). Left: CR-1 measurement (anteriorposterior diameter/Latero-lateral diameter) Right: Perpendicular alignment for CR-1 measurement. Axial T1-weigthed MR image at the level of the foramen magnum and sagittal T2-weighted image in the midline (below). Left: CR-2 measurement (spinal cord area [yellow]/foramen magnum area $\times 100)$. Right: Cervicomedullary angle.

Table 1: Characteristics of patients with syndromic craniosynostosis and controls

\begin{tabular}{lcc}
\hline & $\begin{array}{c}\text { Syndromic Craniosynostosis } \\
(\boldsymbol{n}=122)\end{array}$ & $\begin{array}{c}\text { Controls } \\
(\boldsymbol{n}=131)\end{array}$ \\
\hline Syndrome (No. of cases) & & NA \\
Apert & 34 & NA \\
Crouzon & 65 & NA \\
Muenke & 12 & NA \\
Saethre-Chotzen & 11 & 9.90 (range, 0.01-18.20) \\
Mean age (yr) & 5.70 (range, 0.24-18.92) & 0.64 (range, 0.43-0.87) \\
Mean CR-1 & 0.63 (range, 0.32-1.03) & 0.28 (range, 0.08-0.80) \\
Mean CR-2 & 0.41 (range, 0.12-1.00) & 157.07 (range, 136.04-174.21) \\
Mean CMA & 149.92 (range, 122.06-167.78) & 157.0
\end{tabular}

Note:-NA indicates not applicable.

\section{Statistical Analysis}

The analysis was performed in $\mathrm{R}$ statistical software (Version 3.6.1; package nlme, Version 3.1; package ggplot2, Version 3.2.1; http://www.r-project.org). Linear mixed models were developed to correct for repeated measures, age, sex, and syndrome (ie, Apert, Crouzon, Muenke. and Saethre-Chotzen syndromes). The necessity of interaction terms was tested through the omnibus method and subsequently was not entered in all models. Normality was assured by evaluation of the QQ-plots.

We developed 3 separate models comparing patients with syndromic craniosynostosis with controls. CR-1, CR-2, and CMA were the outcome variables in these models; age, sex and syndrome were entered as predictors.

In the fourth model, oAHI was the outcome variable. The CR-1, CR-2, CMA, and age were entered as the predictors. Only patients with craniosynostosis were included in this analysis. Because OSA in syndromic craniosynostosis is caused by a multilevel obstruction, ${ }^{30}$ we corrected for upper airway obstruction. The presence of upper airway obstruction was evaluated by reviewing endoscopy results and the physical examination by the plastic surgeons and Ear, Nose and Throat doctors.

In the fifth and last model, the outcome variable was cAHI, whereas the CR-1, CR-2, CMA, and age were the predictors. Again, only the patients with craniosynostosis were included in this model.

\section{RESULTS}

One hundred ninety-five MR images and PSGs were identified. After we applied the maximum time interval, $122 \mathrm{MR}$ images and sleep studies in 89 patients were paired, of whom 44 patients were included in earlier studies on sleep disturbances in syndromic craniosynostosis. ${ }^{8,11,23}$ Additionally, 131 controls were included. See Table 1 for the patient and control characteristics and Table 2 for the comparison of the parameters in syndromic craniosynostosis versus controls. The Online Figure depicts the distribution of the spinal cord parameters for each syndrome.

Abnormal cervical spinal cord parameters were observed in 8 patients (ie, $9 \%$ of the patients). The CR- 1 was abnormal in 1 patient who also had an abnormal CMA. The CMA was deviant in 8 patients and significantly differed from that in controls in Apert, Crouzon, and Saethre-Chotzen syndromes. The mean CR-2 was 0.41 (range, 0.12-1.00) and was significantly higher in patients with Crouzon syndrome compared with controls.

All measurements derived from the 122 paired MR images and sleep studies were entered in the analysis. The mean age at the PSG was 5.7 years (range, 0.02-18.9 years). The mean oAHI was 3.2 (range, 0.074.6); obstructive sleep apnea (an oAHI of $>1$ ) was diagnosed in 41 (34\%) patients. The mean cAHI was 1.3 (range, 0.0-13.2); a cAHI of $>5.0$ was diagnosed in 5 patients. Two of them also had severe OSA, 2 of them 
Table 2: $\beta$ coefficients and $\boldsymbol{P}$ values of the comparisons between patients with syndromic craniosynostosis and controls

\begin{tabular}{llll}
\hline & \multicolumn{1}{c}{ CR-1 } & \multicolumn{1}{c}{ CR-2 } & \multicolumn{1}{c}{ CMA } \\
\hline Apert & $-0.02, P=.39$ & $1.9, P=.64$ & $-4.4, P=.01^{\mathrm{a}}$ \\
Crouzon & $0.02, P=.24$ & $27.6, P<.001^{\mathrm{a}}$ & $-10.2, P<.001^{\mathrm{a}}$ \\
Muenke & $-0.01, P=.77$ & $11.1, P=.07$ & $-4.1, P=.11$ \\
Saethre-Chotzen & $0.05, P=.13$ & $0.6, P=.92$ & $-5.2, P=.049^{\mathrm{a}}$ \\
\hline a &
\end{tabular}

were younger than 1 year of age, and 1 was both younger than 1 year of age and had severe OSA.

\section{Interrater Reliability}

The intraclass correlation coefficient was 0.77 for CR-1 and 0.96 for CR-2 and the cervicomedullary angle.

\section{Association between Cervical Spinal Cord Morphology and Sleep Studies}

The CR-1, CR-2, CMA, and age were not associated with the oAHI ( $P=.12, P=.18, P=.11$, and $P=.62$, respectively).

Age was inversely associated with cAHI $(P=.02)$, whereas CR-1, CR-2, and the CMA were not associated with the cAHI ( $P=.47, P=.75$, and $P=.44$ respectively).

The patient with a CR-1 of $<0.40$ did not have OSA or central sleep apnea. Seven of the patients with an abnormal CMA had Crouzon syndrome, and 1 had Apert syndrome: One of these patients had moderate OSA, 2 had mild OSA, and the other 5 patients did not have OSA. The cAHI was $<5$ in all of these patients.

\section{DISCUSSION}

This study shows that the prevalence of cervical spinal cord compression in syndromic craniosynostosis is low (9\%). Moreover, cervical spinal cord compression parameters are correlated to sleep disturbances.

The spinal cord morphology at the level of the dens (CR-1) was comparable with that of controls, a finding indicating that the altered position of the dens with respect to the foramen magnum does not cause cervical spinal cord compression at this level. In contrast, crowding at the level of the foramen magnum as measured with the CR-2 was found in patients with Crouzon syndrome. The higher prevalence of tonsillar herniation in this group compared with the normative population and the other craniosynostosis syndromes explains this finding (den Ottelander et al, unpublished data). ${ }^{31-33}$ The CMA was significantly smaller in Apert, Crouzon, and Saethre-Chotzen syndromes, explained by the skull base deformation that is known to exist in these syndromes. $^{34-36}$

Age correlated significantly with the cAHI; this finding is to be expected because central apneas are physiologic in neonates and young infants and the finding is in line with previous research. ${ }^{8,23,29}$ In contrast, none of the measurements were associated with the oAHI and CAHI, a finding for which there are several explanations. First, cervical spinal cord compression might be absent in patients with syndromic craniosynostosis because CR-1 was comparable with that in the normative population and was only abnormal in 1 patient. Moreover, CR-2 and CMA might be significantly different compared with controls, but to a limited severity, not causing symptomatic myelopathy. Previous research affirms this theory regarding the correlation between hindbrain herniation and the CR-2, because hindbrain herniation did not correlate with sleep-disordered breathing in that study. ${ }^{23}$ Additionally, symptomatic myelopathy is described in patients with a CMA $<135^{\circ}, 30$ which we found in only 8 patients in our study population, and these patients did not show abnormalities on PSGs. A second explanation for not finding an association between cervical spinal cord parameters and sleep study results might be that previous studies correlated the CR-1 and CMA to symptomatic myelopathy, not describing sleep-disordered breathing. ${ }^{26,28}$ Consequently, it is possible that these parameters do correlate with symptomatic myelopathy, but not with sleepdisordered breathing.

The intraclass correlation coefficient was 0.77 for CR- 1 and 0.96 for CR-2 and the cervicomedullary angle. The difference in interrater reliability can be explained by the extra step necessary to perform the CR-1 measurement because the images for this measurement were aligned perpendicular to the spinal cord in the sagittal plane.

An important limitation of the statistical analysis on the association between sleep disturbances and cervical spinal cord parameters includes the low prevalence of cervical spinal cord compression, which limits the power to reject these associations. However, only 2 of the 9 the patients who did show compression on MR images had moderate/severe OSA, and none had central sleep apnea; this finding strengthens the hypothesis that there is no association. Second, the prevalence of central sleep apnea was low; thus, a correlation would be even harder to find with the current data. However, in the few patients with central sleep apnea, its presence could be linked to age and OSA, also affirming the hypothesis that there is no correlation.

Our study results confirm the low prevalence of central sleep apnea in syndromic craniosynostosis and the absence of an association between cerebellar tonsillar herniation and sleep disturbances. ${ }^{11,23}$ Additionally, we show that the prevalence of cervical spinal cord compression is low. In patients with syndromic craniosynostosis, polysomnographies are a part of the standard of care because of the high prevalence of obstructive sleep apnea. Considering this and the low prevalence of cervical spinal cord compression and central sleep apneas in our study cohort, we would still recommend performing an additional polysomnography in case of evidence of cervical spinal cord compression on MR imaging studies.

\section{CONCLUSIONS}

The prevalence of cervical spinal cord compression in syndromic craniosynostosis is low, and cervical spinal cord compression parameters are not correlated with sleep disturbances. However, considering the high prevalence of obstructive sleep apnea in syndromic craniosynostosis and the low prevalence of deviant cervical spinal cord parameters and central sleep apnea in our cohort, we would still recommend performing an additional 
polysomnography in case of signs of cervical spinal cord compression on MR imaging studies.

\section{REFERENCES}

1. Johnson D, Wilkie AOM. Craniosynostosis. Eur J Hum Genet 2011;19:369-76 CrossRef Medline

2. Fearon JA. Evidence-based medicine: craniosynostosis. Plast Reconstr Surg 2014;133:1261-75 CrossRef Medline

3. Reardon W. Craniosynostosis: diagnosis, evaluation and management. J Med Genet 2000;37:727-27 CrossRef Medline

4. Maliepaard M, Mathijssen IM, Oosterlaan J, et al. Intellectual, behavioral, and emotional functioning in children with syndromic craniosynostosis. Pediatrics 2014;133:e1608-15 CrossRef Medline

5. Agochukwu NB, Solomon BD, Muenke M. Hearing loss in syndromic craniosynostoses: introduction and consideration of mechanisms. Am J Audiol 2014;23:135-41 CrossRef Medline

6. Spruijt B, Joosten KF, Driessen C, et al. Algorithm for the management of intracranial hypertension in children with syndromic craniosynostosis. Plast Reconstr Surg 2015;136:331-40 CrossRef Medline

7. Collmann H, Sorensen N, Krauss J. Hydrocephalus in craniosynostosis: a review. Childs Nerv Syst 2005;21:902-12 CrossRef Medline

8. Driessen C, Joosten KF, Bannink N, et al. How does obstructive sleep apnoea evolve in syndromic craniosynostosis? A prospective cohort study. Arch Dis Child 2013;98:538-43 CrossRef Medline

9. Hayward R. Venous hypertension and craniosynostosis. Childs Nerv Syst 2005;21:880-88 CrossRef Medline

10. den Ottelander BK, de Goederen R, van Veelen MC, et al. Muenke syndrome: long-term outcome of a syndrome-specific treatment protocol. J Neurosurg Pediatr 2019 Jul 19. [Epub ahead of print] CrossRef Medline

11. Driessen C, Mathijssen IM, De Groot MR, et al. Does central sleep apnea occur in children with syndromic craniosynostosis? Respir Physiol Neurobiol 2012;181:321-25 CrossRef Medline

12. Freezer NJ, Bucens IK, Robertson CF. Obstructive sleep apnoea presenting as failure to thrive in infancy. J Paediatr Child Health 1995;31:172-75 CrossRef Medline

13. O'Brien LM, Mervis CB, Holbrook CR, et al. Neurobehavioral correlates of sleep-disordered breathing in children. I Sleep Res 2004;13:165-72 CrossRef Medline

14. Marcus CL, Greene MG, Carroll JL. Blood pressure in children with obstructive sleep apnea. Am J Respir Crit Care Med 1998;157:10981103 CrossRef Medline

15. Crabtree VM, Varni JW, Gozal D. Health-related quality of life and depressive symptoms in children with suspected sleep-disordered breathing. Sleep 2004;27:1131-38 CrossRef Medline

16. Franco RA Jr, Rosenfeld RM, Rao M. First place-resident clinical science award 1999: quality of life for children with obstructive sleep apnea. Otolaryngol Head Neck Surg 2000;123:9-16 CrossRef Medline

17. Petersen MC, Wolraich M, Sherbondy A, et al. Abnormalities in control of ventilation in newborn infants with myelomeningocele. J Pediatr 1995;126:1011-15 CrossRef Medline

18. Amin R, Sayal P, Sayal A, et al. The association between sleep-disordered breathing and magnetic resonance imaging findings in a pediatric cohort with Chiari 1 malformation. Can Respir J 2015;22:31-36 CrossRef Medline
19. Dhamija R, Wetjen NM, Slocumb NL, et al. The role of nocturnal polysomnography in assessing children with Chiari type I malformation. Clin Neurol Neurosurg 2013;115:1837-41 CrossRef Medline

20. Ferre Maso A, Poca MA, de la Calzada MD, et al. Sleep disturbance: a forgotten syndrome in patients with Chiari I malformation. Neurologia 2014;29:294-304 CrossRef Medline

21. Khatwa U, Ramgopal S, Mylavarapu A, et al. MRI findings and sleep apnea in children with Chiari I malformation. Pediatr Neurol 2013;48:299-307 CrossRef Medline

22. Leu RM. Sleep-related breathing disorders and the Chiari 1 malformation. Chest 2015;148:1346-52 CrossRef Medline

23. Driessen C, Joosten KF, Florisson JM, et al. Sleep apnoea in syndromic craniosynostosis occurs independent of hindbrain herniation. Childs Nerv Syst 2013;29:289-96 CrossRef Medline

24. Tubbs RS. Definitions and Anatomic Considerations in Chiari I Malformation and Associated Syringomyelia. Neurosurg Clin N Am 2015;26:487-93 CrossRef Medline

25. Ridder T, Anderson RC, Hankinson TC. Ventral decompression in Chiari malformation, basilar invagination, and related disorders. Neurosurg Clin N Am 2015;26:571-78 CrossRef Medline

26. Kadanka Z Jr, Adamova B, Kerkovsky M, et al. Predictors of symptomatic myelopathy in degenerative cervical spinal cord compression. Brain Behav 2017;7:e00797 CrossRef Medline

27. Wang $S$, Wang $C$, Passias $P G$, et al. Interobserver and intraobserver reliability of the cervicomedullary angle in a normal adult population. Eur Spine J 2009;18:1349-54 CrossRef Medline

28. Bundschuh C, Modic MT, Kearney F, et al. Rheumatoid arthritis of the cervical spine: surface-coil MR imaging. AJR Am J Roentgenol 1988;151:181-87 CrossRef Medline

29. Berry RB, Budhiraja R, Gottlieb DJ, et al; American Academy of Sleep Medicine. Rules for scoring respiratory events in sleep: update of the 2007 AASM Manual for the Scoring of Sleep and Associated Events: deliberations of the Sleep Apnea Definitions Task Force of the American Academy of Sleep Medicine. J Clin Sleep Med 2012;8:597619 CrossRef Medline

30. Doerga PN, Spruijt B, Mathijssen IM, et al. Upper airway endoscopy to optimize obstructive sleep apnea treatment in Apert and Crouzon syndromes. J Craniomaxillofac Surg 2016;44:191-96 CrossRef Medline

31. Cinalli G, Spennato P, Sainte-Rose C, et al. Chiari malformation in craniosynostosis. Childs Nerv Syst 2005;21:889-901 CrossRef Medline

32. Smith BW, Strahle J, Bapuraj JR, et al. Distribution of cerebellar tonsil position: implications for understanding Chiari malformation. J Neurosurg 2013;119:812-19 CrossRef Medline

33. Rijken BF, Lequin MH, van der Lijn F, et al. The role of the posterior fossa in developing Chiari I malformation in children with craniosynostosis syndromes. J Craniomaxillofac Surg 2015;43:81319 CrossRef Medline

34. McGrath J, Gerety PA, Derderian CA, et al. Differential closure of the spheno-occipital synchondrosis in syndromic craniosynostosis. Plast Reconstr Surg 2012;130:681e-89 CrossRef Medline

35. Paliga JT, Goldstein JA, Vossough A, et al. Premature closure of the spheno-occipital synchondrosis in Pfeiffer syndrome: a link to midface hypoplasia. J Craniofac Surg 2014;25:202-05 CrossRef Medline

36. Rijken BF, Lequin MH, Van Veelen ML, et al. The formation of the foramen magnum and its role in developing ventriculomegaly and Chiari I malformation in children with craniosynostosis syndromes. J Craniomaxillofac Surg 2015;43:1042-48 CrossRef Medline 